\title{
In Vitro Dissolution Profile of Two Commercially Available Iron Preparations
}

\author{
José P.H. Patrício, ${ }^{1}$ Cristina Santos ${ }^{2}$ and Rui Cerdeira ${ }^{2}$
}

1 Department of Research and Development, BIAL-Portela \& C ${ }^{a}$, S.A., S. Mamede Coronado, Portugal

2 Quality Department, BIAL-Portela \& C ${ }^{a}$, S.A., S. Mamede Coronado, Portugal

\section{Abstract}

\section{Introduction}

Iron deficiency is the most common and widespread nutritional disorder in the world. ${ }^{[1-4]}$
Background: Current scientific evidence indicates that anemia in pregnancy, regardless of severity, is associated with an increased risk of maternal and fetal mortality. There is little published information about the bioavailability and bioequivalence of formulations containing both iron and folic acid. However, in vitro dissolution studies can provide important information on the likely relative bioavailability of various formulations.

Aim: The objective of our study was to compare the in vitro dissolution of two similar commercially available formulations of iron- and folic acid-containing supplements, Folifer ${ }^{\circledR}$ (Bialport - Produtos Farmacêuticos, S.A., Portugal) and Ferroliver ${ }^{\circledR}$ (SM Pharma c.a., Venezuela), in order to determine the in vitro availability of their iron content. Folifer ${ }^{\circledR}$ and Ferroliver ${ }^{\circledR}$ were chosen because they contained similar amounts of elemental iron.

Methods: The amount of iron released from each tablet was evaluated over a 4-hour period in three dissolution media replicating gastric or intestinal juices with $\mathrm{pH}$ values ranging from 1.5 to 6.9 . The samples were then titrated with a solution of cerium ammonium sulfate in order to calculate the amount of iron released in each specific $\mathrm{pH}$ condition. The percentage of dissolved iron was calculated as a cumulative frequency, using the percentage of dissolved iron at all timepoints. The dissolution similarity between the two commercially available formulations was evaluated using the $f_{2}$ statistic formula.

Results: During a 4-hour dissolution test, Folifer ${ }^{\circledR}$ released $59.4 \mathrm{mg}$ of iron compared with $48.5 \mathrm{mg}$ released by Ferroliver ${ }^{\circledR}$. The value obtained for the similarity factor, an indicator of likely bioequivalence, was 41 .

Conclusion: These data suggest that Folifer $^{\circledR}$ releases more iron than Ferroliver ${ }^{\circledR}$, and that the two formulations are not equivalent in vitro. The superior dissolution of ferrous sulfate with Folifer ${ }^{\circledR}$ compared with ferrous fumarate in Ferroliver ${ }^{\circledR}$ might be responsible for the observed difference. 
gathered between 1993 and 2005, estimated the worldwide prevalence of anemia in pregnant women to be $41.8 \%$. ${ }^{[5]}$

Recent evidence suggests that all grades of anemia increase the risk of death. ${ }^{[6]}$ Severe anemia is associated with an increased risk of maternal and child mortality. ${ }^{[5]}$ Severe anemia may directly cause maternal death from heart failure, but moderate anemia is also a factor that can influence a woman's ability to prevent and/or recover from complications in pregnancy or post-partum, such as hemorrhage and infection. ${ }^{[6]}$

The risk of folate deficiency is also increased during pregnancy (mainly during periods of rapid fetal growth) and lactation (when folate is lost in breast milk). ${ }^{[7]}$ In pregnancy, among other complications, the risk of neural tube defects ${ }^{[8]}$ may be increased up to 10 -fold, depending on folate status. ${ }^{[7]}$

Furthermore, deficiencies of folate and iron usually occur together, are particularly common during pregnancy, lactation, and the post-partum period, and are the two leading causes of nutritional deficiency anemia. ${ }^{[9]}$ However, it has been reported that concomitant administration of iron and folic acid facilitates a better physiological response to the treatment of iron deficiency in pregnancy than iron alone. ${ }^{[10]}$

Neither iron nor folic acid has been shown to be pharmacologically active, but both play complex roles in the normal metabolism of the body. Both iron and folate are necessary for the normal functioning of the hematopoietic system, as well as many other essential metabolic processes. ${ }^{[7]}$

The WHO recommends universal supplementation for all pregnant women with iron $60 \mathrm{mg} /$ day and folic acid $400 \mu \mathrm{g} / \mathrm{day}$, from as early as possible in pregnancy. ${ }^{[11]}$ However, despite this, anemia continues to be one of the most common causes of disease in pregnancy. ${ }^{[6,11]}$

Different combinations of iron- and folic acidcontaining supplements are commercially available, some of which contain similar amounts of elemental iron. However, there are no published studies comparing the bioavailability and bioequivalence of these combinations containing both iron and folic acid. Indeed, evaluating the in vivo bioequivalence of such supplements can be difficult to manage, because iron is both a phys- iological constituent of the body and is present in variable quantities in food. Similarly, the formulation (e.g. a slow-release formulation) and solubility of the particular iron salt can also influence the bioavailability. ${ }^{[12-14]}$ In these cases, in vitro dissolution may be a more appropriate assessment method.

Furthermore, iron-containing drugs have undesirable side effects on the gastric mucosa; therefore, it is common to design oral slow-release formulations in order to improve tolerability and adherence to treatment. ${ }^{[15]}$ Under these conditions, it might be appropriate to evaluate the release rate of iron over time by performing a dissolution test. ${ }^{[16]}$ These tests evaluate the in vitro dissolution rate (giving important information on the probable bioavailability of the products) and allow assessment of the degree of similarity between products to indicate their in vitro bioequivalence. ${ }^{[17]}$

The aim of this study was to compare the in vitro dissolution of six tablets of two iron- and folic acidcontaining supplements, Folifer ${ }^{\circledR}$ and Ferroliver $^{\circledR}$.

\section{Materials and Methods}

Of the supplements commercially available for iron-deficiency anemia prevention, two iron- and folic acid-containing combinations were selected, which contained different iron salts but similar amounts of elemental iron. Folifer ${ }^{\circledR}$ (Bialport Produtos Farmacêuticos, S.A., Portugal) is available in film-coated tablet form, each tablet consisting of a central core, containing approximately $90 \mathrm{mg}$ of iron (as ferrous sulfate granules), and $1 \mathrm{mg}$ of folic acid. For comparison purposes, Ferroliver $^{\circledR}$ (SM Pharma c.a., Venezuela) was used, another ironcontaining supplement in tablet form. Ferroliver ${ }^{\circledR}$ contains slightly more iron $(99 \mathrm{mg}$, as ferrous fumarate) compared with Folifer ${ }^{\circledR}$ and a different amount of folic acid $(400 \mu \mathrm{g})$, as well as containing other compounds, including $0.0005 \mathrm{mg}$ of vitamin $\mathrm{B}_{12}$ and $1 \mathrm{mg}$ of copper sulfate.

\section{Reagents and Solutions}

The following reagents and solutions were used: concentrated hydrochloric acid 35-37\% (Sigma), iron sulfate (II) [Merck], concentrated sulfuric acid 95-97\% (Merck), sodium hydroxide 
(Sigma), monopotassium phosphate (Merck), ammonium sulfate (Merck), cerium (Merck), potassium iodide (Sigma), sodium thiosulfate (Merck), soluble starch (Sigma), and mercuric iodide (Sigma).

The reagents and solutions were prepared as follows:

Solution of ammonium sulfate and $0.1 \mathrm{M}$ cerium: $65 \mathrm{~g}$ of ammonium sulfate and cerium was dissolved and mixed with $30 \mathrm{~mL}$ of concentrated sulfuric acid and $500 \mathrm{~mL}$ of water. The mixture was cooled and a further $1000 \mathrm{~mL}$ of water was added. Then, $25 \mathrm{~mL}$ of ammonium sulfate and cerium was added to $2 \mathrm{~g}$ of potassium iodide and $150 \mathrm{~mL}$ of water. This was titrated immediately with $0.1 \mathrm{M}$ sodium thiosulfate, using $1 \mathrm{~mL}$ of starch solution as an indicator.

Solution of ammonium sulfate and $0.01 \mathrm{M}$ cerium: $50 \mathrm{~mL}$ of ammonium sulfate and $0.1 \mathrm{M}$ cerium was diluted with $500 \mathrm{~mL}$ water.

Starch solution: $1.0 \mathrm{~g}$ of soluble starch was ground with $5 \mathrm{~mL}$ of water and poured, stirring constantly, into $100 \mathrm{~mL}$ of boiling water, to which $10 \mathrm{mg}$ of mercuric iodide was added.

Gastric juice ( $p H$ 1.5): $90 \mathrm{~mL}$ of concentrated hydrochloric acid and $84 \mathrm{~mL}$ of $10 \mathrm{M}$ sodium hydroxide were transferred to a $10 \mathrm{~L}$ container. This mixture was stirred, and approximately $9 \mathrm{~L}$ of water was added until the $\mathrm{pH}$ reached $1.50 \pm 0.05$. The solution was then made up to $10 \mathrm{~L}$ with water.

Intestinal juice ( $p H 4.5): 8.7 \mathrm{~g}$ of monopotassium phosphate was added to a $10 \mathrm{~L}$ container. Water was added to the mixture, which was stirred and diluted to $1 \mathrm{~L} .38 \mathrm{~mL}$ of $10 \mathrm{M}$ sodium hydroxide and $30 \mathrm{~mL}$ of concentrated hydrochloric acid were then added. The solution was stirred and adjusted until the $\mathrm{pH}$ was $4.50 \pm 0.05$. The solution was then made up to $10 \mathrm{~L}$ with water.

Intestinal juice ( $p H$ 6.9): The same procedure was used as described in preparation of the intestinal juice $\mathrm{pH} 4.5$, except the $\mathrm{pH}$ was adjusted to $6.90 \pm 0.05$.

\section{Equipment}

Weighing was carried out using a Mettler Toledo XS205 balance. The dissolution tests were carried out using the Vankel VK700 dissolution testing station, while the titrimetric determination of iron was evaluated using a Radiometer TIM800 automatic titrator.

\section{In Vitro Dissolution Test}

The amount of iron released from each tablet was evaluated over a 4-hour period, using the Vankel VK700 dissolution testing station and one of three dissolution media replicating gastric or intestinal juices with $\mathrm{pH}$ values ranging from 1.5 to 6.9 . The test was performed by transferring $750 \mathrm{~mL}$ of gastric juice $(\mathrm{pH} 1.5)$ to six dissolution vessels and allowing the temperature to stabilize at $37.0 \pm 0.5^{\circ} \mathrm{C}$. One tablet was placed in each rotating basket within each vessel to begin the dissolution test at $50 \mathrm{rpm}$. After 1 hour, a $200 \mathrm{~mL}$ sample was removed from each of the six dissolution vessels and accurately measured, and $20 \mathrm{~mL}$ of sulfuric acid $1 \mathrm{M}$ was added. To quantify the amount of iron released, this sample was then titrated with a solution of cerium ammonium sulfate $0.01 \mathrm{M}$, using a platinum electrode as the indicator electrode and mercury as a reference electrode. ${ }^{[18]}$

The remainder of the medium in the dissolution vessel was then discarded and replaced with intestinal juice $\mathrm{pH} 4.5$, which was allowed to stabilize to $37.0 \pm 0.5^{\circ} \mathrm{C}$ for 5 minutes, and the test proceeded for a further 1-hour rotation period to allow further dissolution of the tablet. After 1 hour, another $200 \mathrm{~mL}$ sample was then taken from each vessel and measured precisely, and $20 \mathrm{~mL}$ of sulfuric acid $1 \mathrm{M}$ was added. This was then titrated with a solution of cerium ammonium sulfate $0.01 \mathrm{M}$, using a platinum electrode as the indicator electrode and mercury as a reference electrode. The procedure was then repeated using intestinal juice with a $\mathrm{pH}$ of 6.9 and a rotation period of 2 hours.

These conditions were established in order to have a minimum of three timepoints, covering the early, middle and late stages of the dissolution profile, with the last timepoint corresponding to the plateau of the dissolution profile. ${ }^{[19]}$ Moreover, these three timepoints are sufficient to draw a dissolution profile that can be used to compare the different formulas.

The experimental method was validated as per the International Conference on Harmonisation $(\mathrm{ICH})$ guideline $\mathrm{Q} 2^{[20]}$ and the United States 
Pharmacopeia. ${ }^{[16]}$ Linearity was assessed for the three $\mathrm{pHs}$ by plotting three calibration plots, with a correlation coefficient of 1.0000 . Repeatability and intermediate precision were assessed by analyzing two sets of six tablets on different days, with different analysts. The overall relative standard deviation was less than $10 \%$ as per the validation protocol for the three dissolution media, while the absolute difference between mean dissolution values for each $\mathrm{pH}$ was less than $10 \%$. Accuracy was evaluated for each $\mathrm{pH}$ by spiking placebo with known amounts of iron (II). A mean recovery index within $100 \pm 2 \%$ was obtained for the three dissolution media. Robustness was evaluated by changing the critical parameters of the method. The results obtained were within $100 \pm 5 \%$ of the results obtained under standard conditions.

\section{Statistical Methods}

The percentage of dissolved iron for each tablet at each timepoint was calculated as a cumulative frequency, using the percentage of dissolved iron at all timepoints that had been analyzed up to that point. For each timepoint, the mean percentage of dissolved iron was calculated from the six tablets, together with the relative standard deviation. The mean values were plotted in dissolution curves for the two products under evaluation and allowed comparison by means of the similarity factor, $f_{2}$ (equation 1).

$$
f_{2}=50 \cdot \log \left[\frac{100}{\sqrt{1+\frac{\sum_{t=1}^{t=n}[\bar{R}(t)-\bar{T}(t)]^{2}}{n}}}\right]
$$

where $n=$ number of points (two in this case); $R(t)=$ mean percentage of iron dissolved at time, $t$, for Ferroliver ${ }^{\circledR} ; T(t)=$ mean percentage of iron dissolved at time, $t$, for Folifer ${ }^{\circledR}$.

The similarity factor is a logarithmic reciprocal square root transformation of the sum of squared errors and is a measurement of the similarity in the percentage of dissolution between the two curves. At least three mean dissolution results from both curves obtained at the same timepoints were used for the calculations. An $f_{2}$ value of between 50 and 100 suggests that the two dissolution profiles are similar.

\section{Results}

The results of the dissolution profiles and degree of similarity for the two products are shown in table I and figures 1 and 2.

During the first hour, $29.7 \mathrm{mg}$ and $32.7 \mathrm{mg}$ of iron was released from Folifer $^{\circledR}$ and Ferroliver ${ }^{\circledR}$, respectively. In percentage terms, the release rate was similar, as the iron content of the two supplements was similar. During the second hour, Folifer ${ }^{\circledR}$ showed a higher capacity for releasing iron than Ferroliver $^{\circledR}$, both in absolute terms and in relative terms. After 4 hours, the amounts of iron released by Folifer ${ }^{\circledR}$ and Ferroliver ${ }^{\circledR}$ were $59.4 \mathrm{mg}$ and $48.5 \mathrm{mg}$, respectively.

The mean comparative dissolution profiles of Folifer ${ }^{\circledR}$ and Ferroliver ${ }^{\circledR}$ were also assessed by determining the similarity factor, $f_{2}$, according to the formula shown in equation 1 . The $f_{2}$ value between the two formulations was 41 , showing a lack of similarity and in vitro bioequivalence.

Table I. Mean amount of iron released from two iron- and folic acid-containing supplements, Folifer ${ }^{\circledR}$ and Ferroliver ${ }^{\oplus}$ : results from an in vitro dissolution study

\begin{tabular}{|c|c|c|c|c|c|c|}
\hline \multirow[t]{2}{*}{ Timepoint } & \multicolumn{3}{|c|}{ Folifer $^{(\mathrm{Aa}}(\mathrm{n}=6)$} & \multicolumn{3}{|c|}{ Ferroliver $^{\oplus \mathrm{b}}(\mathrm{n}=6)$} \\
\hline & $\begin{array}{l}\text { Mean D } \\
(\%)\end{array}$ & $\begin{array}{l}\text { RSD } \\
(\%)\end{array}$ & $\begin{array}{l}\text { Mean Qt } \\
(\mathrm{mg})\end{array}$ & $\begin{array}{l}\text { Mean D } \\
(\%)\end{array}$ & $\begin{array}{l}\text { RSD } \\
(\%)\end{array}$ & $\begin{array}{l}\text { Mean Qt } \\
(\mathrm{mg})\end{array}$ \\
\hline 1 hour $(\mathrm{pH}=1.5)$ & 33 & 8.0 & 29.7 & 33 & 7.6 & 32.7 \\
\hline 2 hours $(\mathrm{pH}=4.5)$ & 63 & 5.2 & 56.7 & 43 & 7.7 & 42.6 \\
\hline 4 hours $(\mathrm{pH}=6.9)$ & 66 & 5.1 & 59.4 & 49 & 7.7 & 48.5 \\
\hline \multicolumn{7}{|c|}{ a Containing $90 \mathrm{mg}$ of iron as ferrous sulfate. } \\
\hline \multicolumn{7}{|c|}{ b Containing $99 \mathrm{mg}$ of iron as ferrous fumarate. } \\
\hline \multicolumn{7}{|c|}{$\mathbf{D}=$ dissolution; $\mathbf{Q} \mathbf{t}=$ amount of dissolved iron; $\mathbf{R S D}=$ relative standard deviation } \\
\hline
\end{tabular}




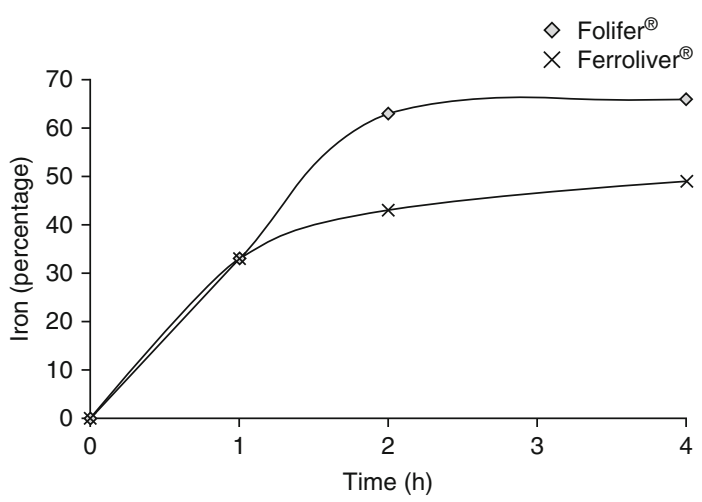

Fig. 1. Dissolution profiles showing the mean percentage of iron released over a 4-hour time period for Folifer ${ }^{\circledR}$ and Ferroliver ${ }^{\circledR}$.

\section{Discussion}

In vitro dissolution studies can provide important information on bioavailability and bioequivalence of various formulations. A dissolution test can be used as a tool to identify formulation factors that influence, and may have a crucial effect on, the bioavailability of a drug. Appropriate in vitro dissolution testing may be used in place of in vivo bioequivalence testing. Accordingly, dissolution testing should be investigated at different $\mathrm{pH}$ values (normally $\mathrm{pH} 1.2,4.5$, and 6.8).

Results from our in vitro dissolution study showed Folifer ${ }^{\circledR}$ was superior to Ferroliver ${ }^{\circledR}$, releasing $59.4 \mathrm{mg}$ versus $48.5 \mathrm{mg}$ of iron over a 4-hour period, respectively, indicating that Folifer ${ }^{\circledR}$ is likely to have increased bioavailability compared with Ferroliver ${ }^{\circledR}$. This result is even more surprising considering that Ferroliver $^{\circledR}$ has a slightly higher elemental iron content.

In this respect, the role of the different iron salts in each drug - ferrous sulfate (in Folifer ${ }^{\circledR}$ ) and ferrous fumarate (in Ferroliver ${ }^{\circledR}$ ) - should be noted. Ferrous sulfate has an improved dissolution profile compared with ferrous fumarate because of its superior degree of solubility in acid. ${ }^{[21]}$ This difference is likely to be the main reason for the observed results and the lack of equivalence between the two products.

However, since the two products differ slightly in their chemical composition, we cannot exclude the possibility of bias in the study. While we rec- ognize that this is a potential limitation of this stu$\mathrm{dy}$, there is no known scientific rationale for folic acid, vitamin $\mathrm{B}_{12}$, or copper sulfate significantly influencing the in vitro dissolution of iron. The selectivity of cerimetric titration for the quantitation of iron (II) in the presence of inert excipients was demonstrated in the validation results. Excipients and other active ingredients found in the formulas were not expected to have any relevant influence on the assay, as they either did not have any relevant oxidation-reduction behavior, or they were present at very low levels relative to the amount of iron.

Finally, the information that arises from application of the formula for calculating the similarity factor (equation 1) shows both drugs have different in vitro dissolution profiles and so are unlikely to be bioequivalent.

This study reinforces the importance and differentiation of ferrous sulfate and ferrous fumarate as iron salts. Previous evidence suggests that different iron salts show similar tolerability in clinical use. ${ }^{[22]}$ In two studies comparing the absorption of ferrous sulfate and ferrous fumarate from fortified milk-based drinks, one study found that ferrous sulfate was better absorbed than ferrous fumarate, ${ }^{[23]}$ while absorption of ferrous sulfate and ferrous fumarate did not differ significantly in the second study. ${ }^{[24]}$ Given the significant effects that the type of salt may have on in vitro dissolution, ferrous sulfate-containing supplements such as Folifer ${ }^{\circledR}$ may therefore be a better choice for iron/folic acid supplementation

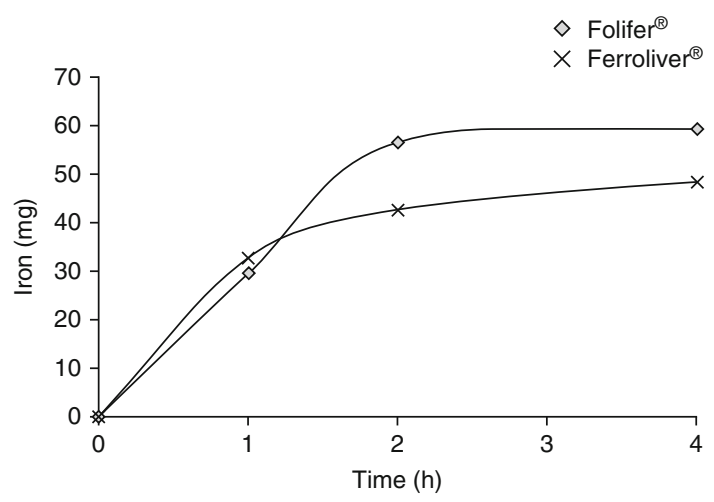

Fig. 2. Dissolution profiles showing the mean absolute amount of iron released over a 4-hour time period for Folifer ${ }^{\circledR}$ and Ferroliver ${ }^{\circledR}$. 
in individuals at risk of iron/folate deficiencies, such as pregnant and lactating women.

\section{Conclusion}

Despite containing similar amounts of elemental iron, Folifer ${ }^{\circledR}$ showed greater dissolution of iron compared with Ferroliver ${ }^{\circledR}$. This study highlights the importance of some iron salts (such as ferrous sulfate) on the bioavailability of iron supplements. Folifer ${ }^{\circledR}$ and Ferroliver ${ }^{\circledR}$ had dissimilar dissolution profiles in vitro; differences in the solubility of ferrous sulfate and ferrous fumarate may explain the lack of equivalence, and this should be considered in clinical practice.

\section{Acknowledgments}

Native English editing was provided by Jane Caple, of inScience Communications, a Wolters Kluwer business, and was funded by BIAL - Portela \& $\mathrm{C}^{\mathrm{a}}$, S.A. This study was funded by BIAL - Portela \& Ca , S.A.

All authors work for BIAL - Portela \& $C^{a}$, S.A. They have no other conflicts of interest that are directly relevant to the content of this study.

\section{References}

1. Ansari T, Ali L, Aziz T, et al. Nutritional iron deficiency in women of child bearing age: what to do? J Ayub Med Coll Abbottabad 2009; 21 (3): 17-20

2. Baltussen R, Knai C, Sharan M. Iron fortification and iron supplementation are cost-effective interventions to reduce iron deficiency in four subregions of the world. J Nutr 2004; 134 (10): 2678-84

3. Garanito MP, Pitta TS, Carneiro JDA. Iron deficiency in adolescence. Rev Bras Hematol Hemoter 2010; 32 Suppl 2: 45-8

4. Hulthen L. Iron deficiency and cognition. Scand J Nutr 2003; 47 (3): 152-6

5. World Health Organization. Worldwide prevalence of anaemia 1993-2005: WHO global database on anaemia [online] Available from URL: http://whqlibdoc.who.int/publications/ 2008/9789241596657_eng.pdf [Accessed 2011 Oct 4]

6. Sanghvi TG, Harvey PW, Wainwright E. Maternal iron-folic acid supplementation programs: evidence of impact and implementation. Food Nutr Bull 2010; 31 (2 Suppl.): S100-7

7. Joint Food and Agriculture Organization/World Health Organization Expert Consultation on Human Vitamin and Mineral Requirements. Vitamin and mineral requirements in human nutrition. 2nd ed [online]. Available from URL: http://whqlibdoc.who.int/publications/2004/9241546123. pdf [Accessed 2012 Feb 28]

8. Oakley Jr GP. Folate deficiency is an 'imminent health hazard' causing a worldwide birth defects epidemic. Birth Defects Res A Clin Mol Teratol 2003; 67 (11): 903-4

9. Marti-Carvajal A, Pena-Marti G, Comunian G, et al. Prevalence of anemia during pregnancy: results of Valencia
(Venezuela) Anemia during Pregnancy Study. Arch Latinoam Nutr 2002; 52 (1): 5-11

10. Juarez-Vazquez J, Bonizzoni E, Scotti A. Iron plus folate is more effective than iron alone in the treatment of iron deficiency anaemia in pregnancy: a randomised, double blind clinical trial. BJOG 2002; 109 (9): 1009-14

11. World Health Organization. Iron deficiency anaemia assessment, prevention, and control: a guide for programme managers. Geneva: World Health Organization, 2001

12. Conrad ME, Umbreit JN. Iron absorption and transport an update. Am J Hematol 2000; 64 (4): 287-98

13. Hahn PF. The relative absorption and utilization of ferrous and ferric iron in anemia as determined with the radioactive isotope. Am J Physiol 1945; 143 (2): 191-7

14. Hurrell R. Optimizing iron compounds and bioavailability. Eur J Clin Nutr 1997; 51 Suppl. 1: S4-8

15. Beard JL. Effectiveness and strategies of iron supplementation during pregnancy. Am J Clin Nutr 2000; 71 (5 Suppl.): 1288S-1294S

16. United States pharmacopeia. 34th ed. Rockville (MD): US Pharmacopeial Convention, 2011

17. European Medicines Agency. Guideline on the investigation of bioequivalence (draft) [online]. Available from URL: http:// www.ema.europa.eu/docs/en_GB/document_library/Scientific guideline/2009/09/WC500003011.pdf [Accessed 2011 Oct 19]

18. Heumann WR, Belovic B. Cerimetric titration of iron using mixed indicator. Anal Chem 1957; 29 (8): 1226-7

19. US Food and Drug Administration. Guidance for industry: extended release oral dosage forms: development, evaluation, and application of in vitro/in vivo correlations, 1997 [online]. Available from URL: http://www.fda.gov/down loads/Drugs/GuidanceComplianceRegulatoryInformation/ Guidances/ucm070239.pdf [Accessed 2012 Feb 28]

20. International Conference on Harmonisation of Technical Requirements for Registration of Pharmaceuticals for Human Use. ICH harmonised tripartite guideline: validation of analytical procedures: text and methodology Q2(R1) [online]. Available from URL: http://www.ich.org/fileadmin/ Public_Web_Site/ICH_Products/Guidelines/Quality/Q2_R1/ Step4/Q2_R1_Guideline.pdf [Accessed 2012 Feb 28]

21. Cameron FK. The solubility of ferrous sulphate. J Phys Chem 1930; 34 (4): 692-710

22. McDiarmid T, Johnson ED. Clinical inquiries: are any oral iron formulations better tolerated than ferrous sulfate? J Fam Pract 2002; 51 (6): 576 [online]. Available from URL: http://www. jfponline.com/Pages.asp?AID=1215 [Accessed 2012 Feb 28]

23. Perez-Exposito AB, Villalpando S, Rivera JA, et al. Ferrous sulfate is more bioavailable among preschoolers than other forms of iron in a milk-based weaning food distributed by PROGRESA, a national program in Mexico. J Nutr 2005; 135 (1): 64-9

24. Harrington M, Hotz C, Zeder C, et al. A comparison of the bioavailability of ferrous fumarate and ferrous sulfate in nonanemic Mexican women and children consuming a sweetened maize and milk drink. Eur J Clin Nutr 2011; 65 (1): 20-5

Correspondence: Dr José Pedro Henriques Patrício, Av. Da Siderurgia Nacional - Apartado 19 - 4745-457, S. Mamede Coronado, Portugal.

E-mail: jose.patricio@bial.com 